\title{
Atuação dos conselhos municipais de alimentação escolar na gestão do programa nacional de alimentação escolar ${ }^{1}$
}

\section{Performance of the municipal boards of school meals in the management of the national school meals program}

Maria Angélica Penatti PIPITONE²

Ana Maria Holland OMETTO2

Marina Vieira da SILVA2

Gilma Lucazechi STURION²

Maria Cristina Ortiz FURTUOSO²

Marilia OETTERER ${ }^{2}$

Este trabalho avaliou a atuação dos Conselhos Municipais de Alimentação Escolar, criados para assessorar e fiscalizar o programa de alimentação escolar. Analisando-se informações obtidas entre setembro de 1997 e abril de 1998, em 1378 municípios brasileiros, verificou-se que a atribuição principal dos Conselhos é a fiscalização da aplicação dos recursos destinados ao Programa Nacional de Alimentação Escolar $(76,90 \%$ dos municípios), seguida pelo acompanhamento do Programa nas escolas $(63,45 \%$ ), pela participação na elaboração do cardápio $(50,41 \%)$ e pela assessoria na programação, execução e avaliação do Programa $(38,90 \%)$. 0 ajuste de modelos próbites multivariados identificou variáveis relevantes para a participação dos Conselhos em diferentes atribuições e mostrou que a descentralização do gerenciamento do Programa aumentou a efetividade da atuação dos Conselhos. Contudo, o conjunto dos resultados evidencia a necessidade de uma atuação mais efetiva dos Conselhos Municipais de Alimentação Escolar como espaço de participação popular e de promoção do Programa Nacional de Alimentação Escolar.

Termos de indexação: alimentação escolar, conselho municipal de alimentação escolar, participação comunitária, programas e políticas de nutrição e alimentação.

\footnotetext{
1 Pesquisa no 54.960.536-00 financiada pelo Fundo Nacional de Desenvolvimento da Ciência e Tecnologia/Financiadora de Estudos e Projetos/Banco Internacional de Desenvolvimento.

2 Departamento de Agroindústria, Alimentos e N utrição, Escola Superior de Agricultura "Luiz de Queiroz", Universidade de São Paulo. Campus de Piracicaba, Caixa Postal 09, 13418-900, Piracicaba, SP, Brazil. Correspondência para/Correspondence to: M.A.P.PIPITONE. E-mail: pipitone@carpa.ciagri.usp.br
} 


\section{A B S T R A C T}

This work evaluated the performance of the Municipal Boards of School M eals, created to assist and supervise the school meals program. Through the analysis of the information obtained from September 1997 to April 1998, in 1378 Brazilian cities, it was verified that the Boards' main task is the supervision of the use of the resources assigned to the National School Meals Program (76.90\% of the cities), followed by the monitoring of the Program at schools ( $63.45 \%$ ), by the participation in the elaboration of the menu $(50.41 \%)$ and by the assistance in the planning, execution and evaluation of the Program (38.90\%). The adjustment in the multivariate probit models showed significant variables for the participation of the Boards in different attributions and it proved that the decentralization of the management of the Program increased the efficiency of the Boards' performance. However, the results highlight the need for a more effective performance of the Municipal Boards of School Meals as a tool for the popular participation and the promotion of the National School M eals Program.

Index terms: school feeding, municipal board of school meals, patient participation, nutrition programmes and policies.

\section{N T R O D U Ç Ã O}

A década de 80, com o clima vigente de redemocratização e resgate da dívida social, traz uma profunda modificação das políticas sociais brasileiras, no sentido da descentralização administrativa, diminuição do papel do Estado e estímulo à participação da população no conjunto das ações sociais.

O movimento de descentralização baseia sua trajetória na busca de caminhos que aliem eficiência e eficácia das ações do Estado à participação popular. Desta forma, este processo pressupõe, de acordo com Lobo (1990)1', alterações nos núcleos de poder, levando a uma maior distribuição do poder decisório até então centralizado em poucas mãos. Este movimento prevê, também, o envolvimento das classes populares e a revitalização do poder legislativo como canais de expressão da população, quase sempre incapacitada de se adaptar às exigências "tecnificadas" e burocratizadas dos aparelhos do Estado.

Segundo McLure (1995) ${ }^{2}$, entre os benefícios comumente descritos como resultantes da descentralização constam o maior controle do cidadão sobre as decisões que lhes são afetas e a maior facilidade dos governos locais em reconhecer as necessidades dos seus municípios. Ainda de acordo com este autor, a descentralização pode introduzir uma saudável competição entre os dirigentes municipais, no tocante à capacidade de "mostrar serviços" e exibir os êxitos da forma de administração dos recursos provenientes das esferas estadual ou federal.

Também o relatório do Banco Mundial (Banco Internacional..., 2001) ${ }^{3}$ ressalta a importância da participação popular, considerada indispensável para o sucesso deste processo, pois só através dela é possível concretizar os benefícios potenciais da informação local e garantir que sejam ouvidas e atendidas as necessidades da maioria.

Entretanto, como aponta M cLure (1995)2, a descentralização não deve ser vista isoladamente, como panacéia para a ineficiência das ações do Estado, já que, para a mesma se tornar uma experiência positiva, ela demanda 0 estabelecimento de medidas efetivas de controle, por parte da população, sobre a qualidade do serviço público prestado.

Os Estados de São Paulo e Rio de Janeiro foram pioneiros na introdução de medidas descentralizadoras em seus Programas Estaduais 
de Alimentação Escolar. A partir de 1982, os governadores eleitos iniciaram a municipalização da merenda escolar, repassando verbas estaduais diretamente para as prefeituras municipais.

Quanto ao governo federal, apenas a partir de 1993, durante o governo do Presidente Itamar Franco (1993-1994), teve início a descentralização administrativa do Programa Nacional de Alimentação Escolar (PNAE), diminuindo a atuação do Estado e estimulando a participação popular no conjunto das ações de gestão do citado programa. Além disso, entre os objetivos da descentralização desse Programa constavam a busca da regularidade do fornecimento da merenda, melhoria da qualidade das refeições, atendimento dos hábitos alimentares, diversificação da oferta de alimentos, incentivo à economia local e regional, diminuição dos custos operacionais e estímulo à participação da comunidade local na execução e controle do Programa.

Com esses objetivos foi promulgada a Lei Federal 8913/94, a qual regulamentou a descentralização do PNAE e normatizou o repasse dos recursos do programa para Estados e municípios ${ }^{4}$.

Esses recursos deveriam ser transferidos mediante a celebração de convênios entre a União e os Estados ou entre a União e os municípios, sendo previsto um valor que deveria ser gasto, exclusivamente, na aquisição de gêneros alimentícios, correspondendo a $\mathrm{R} \$ 0,13$ por aluno matriculado no ensino fundamental e em préescolas das redes pública e filantrópica de ensino, durante 200 dias letivos.

A legislação estabeleceu, também, a exigência da constituição dos Conselhos de Alimentação Escolar (CAE), definindo sua composição e competências, especialmente quanto à fiscalização e controle da aplicação dos recursos. Registrou-se, ainda, a instrução para a participação desses Conselhos na elaboração dos cardápios, que deveriam, de acordo com a referida lei, respeitar os hábitos alimentares e as vocações agrícolas regionais e, preferencialmente, conter alimentos in natura.

À União e aos Estados designou-se a atribuição de assistir tecnicamente os municípios e seus Conselhos.

Os Conselhos deveriam ser compostos por representantes do órgão de administração da educação pública, dos professores, dos pais, dos alunos e dos trabalhadores, podendo também incluir representantes de outros segmentos da sociedade local ${ }^{5}$. Essa composição sofreu algumas alterações estabelecidas pela Medida Provisória no 1979-19, de 2 de junho de 2000, quando então - CAE passou a ser constituído por sete membros: um representante do Poder Executivo, um do Legislativo, dois representantes dos professores, dois de pais de alunos e um representante de outro segmento da sociedade.

O fortalecimento da atuação dos Conselhos Municipais de Alimentação Escolar pode ser uma garantia de que os recursos destinados à alimentação escolar não sejam apenas " prefeiturizados". As funções de orientar, fiscalizar e controlar a aplicação dos recursos destinados à merenda, bem como a prerrogativa de interferir nas decisões de compra de produtos e na composição dos cardápios, devem ser exercidas sob pena de comprometer os princípios da descentralização e fragilizar o Programa Nacional de Alimentação Escolar.

Pipitone $(1997)^{6}$ verificou, em um estudo realizado com 70 municípios paulistas, que, nos primeiros anos da descentralização da alimentação escolar, 22,85\% deles tinham Conselhos totalmente inoperantes, criados apenas para atender às exigências legais para obtenção de recursos federais.

Pesquisa realizada em 34 municípios de 8 Estados brasileiros, pelo Instituto Nacional de Estudos e Pesquisas Educacionais e pelo Núcleo de Estudos de Políticas Públicas da Universidade Estadual de Campinas em 1997, também identificou uma participação insuficiente dos Conselhos Municipais na operacionalização do 
Programa Nacional de Alimentação Escolar. Quando participavam, restringiam-se a oferecer sugestões na elaboração dos cardápios, na definição dos produtos a serem adquiridos ou na fiscalização de depósitos e das escolas.

Santos et al. (2000) ${ }^{7}$ em estudo conduzido no biênio 1997-1998, visando a avaliação da atuação do CAE em 44 municípios baianos vinculados ao Programa Comunidade Solidária, também verificaram participação insuficiente do $\mathrm{CAE}$, visto que em $21,9 \%$ das cidades o Conselho não exercia nenhuma atividade, em 34,4\% fiscalizava a aplicação de recursos na merenda, em $12,5 \%$ discutia e definia a compra dos gêneros alimentícios, em 28,6\% avaliava e acompanhava a distribuição da merenda e em $20,6 \%$ realizava atividades de supervisão da qualidade da merenda.

Este trabalho pretende contribuir para a avaliação da atuação dos Conselhos Municipais de Alimentação Escolar, por meio de pesquisa realizada em âmbito nacional, na qual se procurou não somente verificar as funções efetivamente exercidas pelos Conselhos nas diferentes macrorregiões brasileiras, mas também identificar fatores associados ao exercício dessas funções.

\section{MATERIALE MÉTODOS}

Este trabalho faz parte da pesquisa intitulada "Avaliação do Programa de Alimentação Escolar", realizada com o apoio financeiro do Fundo Nacional de Desenvolvimento da Ciência e Tecnologia/Financiadora de Estudos e Projetos/Banco Internacional de Desenvolvimento (FNDC/FINEP/BID).

As informações utilizadas nesse projeto foram obtidas por meio de questionários com 59 questões de ordem técnica, administrativa e financeira enviados, pelo correio, em setembro de 1997, para 4974 municípios brasileiros, endereçados aos Prefeitos das localidades constantes nas listagens fornecidas pelas Delegacias do Ministério da Educação e do Desporto (MEC) existentes nos diferentes Estados ${ }^{8}$.

Obteve-se, até abril de 1998, a devolução de 1378 questionários, o que possibilitou conhecer uma série de aspectos da implementação do PNAE em cerca de $30 \%$ dos municípios brasileiros.

Essas informações constam de um banco de dados, construído utilizando-se o software M icrosoft Access 8.0.

Como os 1378 questionários que constituem a base de dados, doravante denominados por "amostra", não foram obtidos por meio de sorteio, procurou-se caracterizar essas localidades com base em alguns elementos considerados relevantes para a administração do programa de alimentação escolar e compará-los com a totalidade dos municípios brasileiros. Esse procedimento procurou identificar possíveis tendenciosidades da amostra em termos de distribuição regional, do porte (número de habitantes) e da renda familiar per capita dos municípios que a compõem.

Especificamente para a comparação referente ao número de habitantes e renda familiar per capita média foram utilizadas as informações divulgadas pelo Instituto Brasileiro de Geografia e Estatística (IBGE) em 1994 sobre os 4491 municípios brasileiros relacionados na realização do censo demográfico de $1991^{9}$.

Verificou-se a existência de uma certa tendenciosidade da amostra no aspecto regional, pois estão super-representados os municípios da Região Sul (os quais compõem $27,50 \%$ da base de dados e apenas $21,30 \%$ do total de municípios brasileiros) e sub-representados os da Região Nordeste (24,89\% da amostra e 31,30\% do total). Para as demais Regiões, o número de questionários respondidos resultou em uma distribuição regional mais próxima à da totalidade dos municípios: $6,53 \%$ das cidades que compõem a amostra estão na Região Norte, 31,79\% no 
Sudeste e 9,29\% no Centro-Oeste, enquanto no Brasil esses percentuais são, respectivamente, $8,00 \%, 30,82 \%$ e $8,50 \%$.

A comparação entre a renda familiar per capita média (RFPCM e) das localidades amostradas e a da totalidade de municípios brasileiros possibilitou verificar que em todas as Regiões esse rendimento é, em alguma medida, maior para os municípios participantes da amostra. A menor diferença, 0,02 salários mínimos de agosto de 1991, é a encontrada na Região Sul (na qual a RFPCM e dos municípios amostrados é 0,96 salários mínimos e a da totalidade dos municípios dessa Região é 0,94 salários mínimos) e a maior, 0,20 salários mínimos, é observada no Sudeste (onde esses valores são, respectivamente, 1,16 e 0,96 salários mínimos). Para as Regiões Norte, Nordeste e Centro-Oeste a RFPCMe das cidades amostradas foi $0,69,0,39$ e 0,96 salários mínimos, enquanto para a totalidade dos municípios dessas Regiões esses valores são, respectivamente, $0,58,0,36$ e 0,88 salários mínimos.

No tocante ao porte dos municípios, aqueles com menor número de habitantes estão sub-representados na amostra. Assim, enquanto $60,08 \%$ dos municípios brasileiros têm menos de 16 mil habitantes, apenas $52,1 \%$ dos que constam da base de dados têm esse mesmo porte.

De modo geral, pode-se perceber que, a despeito do procedimento não aleatório da constituição da amostra, a tendenciosidade em termos da participação regional, da renda familiar per capita e do porte dos municípios é pouco expressiva.

Assim, objetivando identificar elementos para explicar as diferenças entre os conselhos municipais no tocante ao desempenho de suas atribuições, utilizou-se o ajuste de próbites multivariados.

Esse tipo de modelo é adequado quando a variável dependente é uma binária, que envolvendo decisão do tipo " sim" ou "não", caso em que a utilização do modelo de regressão linear não é apropriada. Este é o uso das variáveis dependentes coletadas neste trabalho, pois o Conselho de Alimentação Escolar pode participar ou não da elaboração do cardápio, pode acompanhar ou não o desenvolvimento do Programa de Alimentação Escolar nas unidades de ensino, etc.

Atentou-se para o fato de que a decisão de desenvolver efetivamente as atribuições pode ser influenciada por algumas características do município, consideradas variáveis explanatórias: a Região à qual pertence, a renda familiar per capita média, o número de habitantes, o partido político do prefeito, a modalidade de descentralização do PNAE, o total de alunos na área rural e na área urbana, o número de refeições servidas por aluno por dia e a vinculação ao Programa Federal intitulado "Comunidade Solidária".

Foram ajustados próbites para as seguintes atribuições: a) a participação do Conselho na elaboração do cardápio; b) a participação na programação, execução e avaliação do Programa; e c) a participação no acompanhamento do PNAE nas unidades escolares.

Assim, se o Conselho vem desenvolvendo a atribuição referida considera-se que $Y=1$ (em caso contrário $Y=0$ ).

No modelo próbite a distribuição normal é assim utilizada:

$$
\text { a probabilidade de } \begin{aligned}
(Y=1) & =\int_{-\infty}^{\beta^{\prime} \mathbf{x}} \phi(t) d t \\
& =\Phi\left(\beta^{\prime} \mathbf{x}\right)
\end{aligned}
$$

Neste modelo a função $\phi \chi$ é a notação usualmente adotada para a distribuição normal padrão, $\chi$ é o conjunto de variáveis explanatórias e $\beta$ são os parâmetros determinados pelo ajuste (Quadro 1). 
Quadro 1. Definição das variáveis explanatórias.

\begin{tabular}{|c|c|}
\hline Variáveis & Definição \\
\hline NO & = 1 se o município está na Região Norte \\
\hline $\mathrm{CO}$ & = 1 se o município está na Região Centro-Oeste \\
\hline SU & = 1 se 0 município está na Região Sul \\
\hline SE & = 1 se 0 município está na Região Sudeste \\
\hline Renda 2 & $=1$ se a RFPCMe do município o classifica no $2^{\circ}$ quinto \\
\hline Renda 3 & = 1 se a RFPCMe do município o classifica no 3 quinto \\
\hline Renda 4 & $=1$ se a RFPCMe do município o classifica no 4 ํ quinto \\
\hline Renda 5 & $=1$ se a RFPCMe do município o classifica no 5 quinto \\
\hline TAM 2 & = 1 se o número de habitantes do município o classifica no 2º quinto \\
\hline TAM 3 & $=1$ se o número de habitantes do município o classifica no 3 o quinto \\
\hline TAM 4 & $=1$ se o número de habitantes do município o classifica no $4^{0}$ quinto \\
\hline TAM 5 & $=1$ se o número de habitantes do município o classifica no 50 quinto \\
\hline PAB & $=1$ se o prefeito pertence a partidos políticos pequenos, coligados ou sem vinculação partidária \\
\hline PSDB & $=1$ se o partido político do prefeito é o PSDB \\
\hline PFL & $=1$ se o partido político do prefeito é o PFL \\
\hline PDT & $=1$ se o partido político do prefeito é o PDT \\
\hline PT & = 1 se o partido político do prefeito é o PT \\
\hline PSB & $=1$ se 0 partido político do prefeito é o PSB \\
\hline PPB & $=1$ se o partido político do prefeito é o PPB \\
\hline PL & $=1$ se 0 partido político do prefeito é o PL \\
\hline PTB & $=1$ se o partido político do prefeito é o PTB \\
\hline Municipalização & = 1 se 0 gerenciamento do PNAE é municipalizado \\
\hline Escolarização & $=1$ se o gerenciamento do PNAE é escolarizado \\
\hline Total rural & = número de alunos beneficiados na área rural \\
\hline Total urbano & = número de alunos beneficiados na área urbana \\
\hline № Ref/Dia & = número de refeições servidas por dia por aluno \\
\hline Comunidade Solidária & = 1 se o município é vinculado ao Programa Comunidade Solidária \\
\hline
\end{tabular}

Nota: PSDB - Partido Social Democrata Brasileiro; PFL - Partido da Frente Liberal; PDT - Partido Democrata Trabalhista; PT - Partido dos Trabalhadores; PSB - Partido Social Brasileiro; PPB - Partido Popular Brasileiro; PL - Partido Liberal; PTB - Partido Trabalhista Brasileiro.

Nota-se que, exceto para o número de alunos matriculados na área rural e na área urbana e para o número de refeições servidas por dia por aluno, as quais são variáveis numéricas (por exemplo: se houver só refeição de entrada ou de intervalo ou almoço, esse número é um; caso haja refeição de entrada e de intervalo ou almoço, esse número é dois) todas as outras variáveis são binárias, podendo assumir o valor um quando 0 município está na categoria mencionada e zero nos demais casos.

Deve-se mencionar que, para o conjunto de variáveis explanatórias consideradas, o grupo de referência compreende os CAE dos municípios localizados na Região Nordeste, no quinto inferior em termos de renda domiciliar per capita média e do número de habitantes, cujo prefeito está vinculado ao $\mathrm{PMDB}$, sem adesão ao processo de descentralização da merenda, e sem vinculação ao Programa Comunidade Solidária.

Os sinais dos coeficientes associados às variáveis explanatórias indicam se elas têm efeito positivo ou negativo na probabilidade de 0 Conselho desempenhar a atribuição avaliada, tomando-se como base a característica considerada para o grupo de referência.

\section{RESULTA DOS E DISCUSSÃO}

Nos municípios pesquisados foram encontradas as seguintes modalidades de descentralização do PNAE: 
a) estadualização, em 51 municípios (3,90\% da amostra), na qual a Secretaria Estadual de Educação é o órgão conveniado com o Fundo Nacional de Desenvolvimento da Educação (FNDE) e executor dos recursos financeiros, repassando os gêneros alimentícios à rede estadual e/ou municipal;

b) municipalização, em 1189 municípios $(90,97 \%)$, na qual o município é o órgão conveniado com o FNDE, executor dos recursos financeiros, que adquire os alimentos e os envia às unidades escolares municipais e/ou estaduais;

c) escolarização, em 44 municípios $(3,37 \%)$, caracterizada pela situação na qual o conveniado com o FNDE é a Secretaria Estadual de Educação, que recebe e repassa os recursos para as escolas da rede pública estadual e municipal, cujas unidades são executoras do Programa;

d) misto, em 23 municípios (1,76\% ), na qual coexistem, em diferentes combinações, as situações de descentralização mencionadas nos tópicos anteriores.

Esses dados evidenciam o avanço do processo de descentralização do PNAE, visto que em $91 \%$ das localidades conveniadas com o FNDE os próprios municípios são os responsáveis pelo gerenciamento desse Programa.

Deve-se notar que, embora menos de $4 \%$ das localidades tenham reportado a modalidade de gerenciamento do Programa na forma escolarizada, esse percentual deve subestimar a participação dessa modalidade nos municípios brasileiros, pois os questionários foram enviados aos prefeitos municipais, os quais podem não tê- los respondido por desconhecerem a operacionalização do Programa nas escolas. Provavelmente, nas 44 localidades relacionadas, a coordenação do Programa é realizada pela administração municipal.

Em 1997, a maioria dos municípios amostrados já havia atendido às exigências do FNDE, criando o Conselho Municipal de Alimentação Escolar (Tabela 1). Embora o CAE esteja presente em mais de $90,0 \%$ das cidades, as diferenças regionais são expressivas, pois variam de $84,34 \%$ para os municípios da Região Norte a $96,76 \%$ para a Região Sudeste.

Logicamente, a instalação desses Conselhos não significa que os mesmos desempenhem suas atribuições a contento. Um primeiro indicativo da atuação efetiva do CAE é a freqüência com a qual ele se reúne. Em cerca de $60 \%$ dos municípios os Conselhos se reúnem mensalmente ou trimestralmente (Tabela 2). Contudo, em 17\% deles as reuniões são apenas esporádicas e em $3 \%$ elas nunca ocorrem.

0 teste de qui-quadrado mostra que as diferenças regionais são estatisticamente significativas, com os Conselhos dos municípios da Região Sul, de modo geral, reunindo-se com menor freqüência $(19,61 \%)$.

Tabela 1. Distribuição dos municípios de acordo com a existência do Conselho M unicipal de Alimentação Escolar e a macrorregião, 1997.

\begin{tabular}{|c|c|c|c|c|c|c|}
\hline \multirow{2}{*}{ Macrorregião } & \multicolumn{2}{|c|}{ Sim } & \multicolumn{2}{|c|}{ Não } & \multicolumn{2}{|c|}{ Total $^{1}$} \\
\hline & $\mathrm{n}$ & $\%$ & $\mathrm{n}$ & $\%$ & $\mathrm{n}$ & $\%$ \\
\hline Norte & 70 & 84,34 & 13 & 15,66 & 83 & 100,0 \\
\hline Nordeste & 301 & 94,65 & 17 & 5,35 & 318 & 100,0 \\
\hline Sudeste & 418 & 96,76 & 14 & 3,24 & 432 & 100,0 \\
\hline Sul & 307 & 86,97 & 46 & 13,03 & 353 & 100,0 \\
\hline Centro-Oeste & 116 & 94,31 & 7 & 5,69 & 123 & 100,0 \\
\hline Total $^{1}$ & 1212 & 92,59 & 97 & 7,41 & 1309 & 100,0 \\
\hline
\end{tabular}

(1) Esse total refere-se ao número de municípios que responderam a questão; $\chi^{2}=37,95$ com 4 graus de liberdade, significativo a $1 \%$. 
Tabela 2. Periodicidade de realização de reunião do Conselho Municipal de Alimentação Escolar por Região, 1997.

\begin{tabular}{|c|c|c|c|c|c|c|c|c|c|c|c|c|}
\hline \multirow{3}{*}{ Periodicidade } & \multicolumn{12}{|c|}{ Regiões } \\
\hline & \multicolumn{2}{|c|}{ Norte } & \multicolumn{2}{|c|}{ Nordeste } & \multicolumn{2}{|c|}{ Sudeste } & \multicolumn{2}{|r|}{ Sul } & \multicolumn{2}{|c|}{ Centro-Oeste } & \multicolumn{2}{|c|}{ Total $^{1}$} \\
\hline & $n$ & $\%$ & $n$ & $\%$ & $\mathrm{n}$ & $\%$ & $\mathrm{n}$ & $\%$ & $\mathrm{n}$ & $\%$ & $n$ & $\%$ \\
\hline Semanal & 0 & 0,00 & 1 & 0,31 & 1 & 0,24 & 0 & 0,00 & 1 & 0,83 & 3 & 0,24 \\
\hline Quinzenal & 1 & 1,35 & 3 & 0,94 & 10 & 2,43 & 3 & 0,96 & 1 & 0,83 & 18 & 1,46 \\
\hline Mensal & 33 & 44,59 & 143 & 44,97 & 159 & 38,69 & 101 & 32,48 & 44 & 36,67 & 480 & 38,90 \\
\hline Trimestral & 15 & 20,27 & 77 & 24,21 & 78 & 18,98 & 65 & 20,90 & 22 & 18,33 & 257 & 20,83 \\
\hline Semestral & 8 & 10,81 & 22 & 6,92 & 46 & 11,19 & 29 & 9,32 & 16 & 13,33 & 121 & 9,81 \\
\hline Esporadicamente & 5 & 6,76 & 42 & 13,21 & 75 & 18,25 & 61 & 19,61 & 22 & 18,33 & 205 & 16,61 \\
\hline Outra periodicidade & 10 & 13,51 & 23 & 7,23 & 29 & 7,06 & 40 & 12,86 & 12 & 10,00 & 114 & 9,24 \\
\hline Nunca & 2 & 2,70 & 7 & 2,20 & 13 & 3,16 & 12 & 3,86 & 2 & 1,67 & 36 & 2,92 \\
\hline Total & 74 & 100,00 & 318 & 100,00 & 411 & 100,00 & 311 & 100,00 & 120 & 100,00 & 1234 & 100,00 \\
\hline
\end{tabular}

(1) Esse total refere-se ao número de municípios que responderam a questão; $\chi^{2}=45,05$ com 32 graus de liberdade, significativo a $10 \%$.

Tabela 3. Atribuições do Conselho Municipal de Alimentação Escolar, segundo a Região, 1997.

\begin{tabular}{|c|c|c|c|c|c|c|c|c|c|c|c|c|}
\hline \multirow{3}{*}{ Atribuiç̧ões } & \multicolumn{12}{|c|}{ Macrorregiões } \\
\hline & \multicolumn{2}{|c|}{ Norte } & \multicolumn{2}{|c|}{ Nordeste } & \multicolumn{2}{|c|}{ Sudeste } & \multicolumn{2}{|c|}{ Sul } & \multicolumn{2}{|c|}{ Centro-Oeste } & \multicolumn{2}{|c|}{ Total } \\
\hline & $\mathrm{n}$ & $\%$ & $\mathrm{n}$ & $\%$ & $n$ & $\%$ & $\mathrm{n}$ & $\%$ & $\mathrm{n}$ & $\%$ & $n$ & $\%$ \\
\hline $\begin{array}{l}\text { Fiscalização da } \\
\text { aplicação dos } \\
\text { recursos }\end{array}$ & 62 & 83,78 & 248 & 77,99 & 306 & 74,45 & 232 & 74,60 & 101 & 84,17 & 949 & 76,90 \\
\hline $\begin{array}{l}\text { Participação na } \\
\text { elaboração dos } \\
\text { cardápios }\end{array}$ & 39 & 52,70 & 181 & 56,92 & 218 & 53,04 & 127 & 40,84 & 57 & 47,50 & 622 & 50,41 \\
\hline $\begin{array}{l}\text { Colaboração na } \\
\text { programação, } \\
\text { execução e avaliação }\end{array}$ & 23 & 31,08 & 101 & 31,76 & 175 & 42,58 & 137 & 44,05 & 44 & 36,67 & 480 & 38,90 \\
\hline $\begin{array}{l}\text { Realização de } \\
\text { pesquisa de impacto }\end{array}$ & 3 & 4,05 & 20 & 6,29 & 34 & 8,27 & 18 & 5,79 & 15 & 12,50 & 90 & 7,29 \\
\hline $\begin{array}{l}\text { Acompanhamento } \\
\text { do programa na } \\
\text { escola }\end{array}$ & 44 & 59,50 & 192 & 60,38 & 264 & 64,23 & 202 & 64,95 & 81 & 67,50 & 783 & 63,45 \\
\hline $\begin{array}{l}\text { Divulgação da } \\
\text { atuação do Conselho }\end{array}$ & 14 & 18,92 & 62 & 19,50 & 91 & 22,14 & 62 & 19,94 & 33 & 27,50 & 262 & 21,23 \\
\hline Não tem participação & 2 & 2,70 & 15 & 4,72 & 29 & 7,06 & 17 & 5,47 & 6 & 5,00 & 69 & 5,59 \\
\hline
\end{tabular}

Foi efetuado um levantamento das atribuições efetivamente desempenhadas pelos membros do CAE (Tabela 3). A atribuição primordial desse Conselho parece ser, indiscutivelmente, a fiscalização da aplicação dos recursos do PNAE. Em 76,90\% dos municípios o CAE desempenha esta função, com destaque para aquelas da Região Centro-Oeste, onde esse percentual atinge $84,17 \%$.

O acompanhamento do Programa na escola, atividade que implica em uma participação constante do Conselho, é realizado em $63,45 \%$ dos municípios. Novamente destacam-se aqueles da Região Centro-Oeste, onde esse percentual é de $67,50 \%$.

A participação na elaboração dos cardápios possibilita ao Conselho verificar se estão sendo respeitados os hábitos alimentares dos usuários do Programa e as vocações agrícolas regionais, bem como comprovar a utilização preferencial de produtos in natura em detrimento dos produtos previamente formulados. Todavia, a despeito da relevância da atribuição, o CAE desempenha essa função em apenas metade das localidades amostradas. As diferenças regionais são elevadas, pois enquanto em $56,92 \%$ dos 
municípios do Nordeste o Conselho tem essa atribuição, na Região Sul esse percentual é de apenas $40,84 \%$.

A divulgação da composição do Conselho e das suas atribuições é importante para os usuários e demais interessados tomarem conhecimento dos canais estabelecidos para o encaminhamento de críticas e sugestões que possam aprimorar o funcionamento do PNAE. Todavia, essa divulgação é realizada em apenas cerca de um quinto dos municípios brasileiros. $M$ ais uma vez a Região Centro-Oeste tem o maior percentual de cidades reportando o desempenho dessa atividade pelo Conselho $(27,50 \%$ ).

Quando se procura identificar os municípios nos quais o CAE tem atuação mais abrangente, colaborando em todas as etapas da implementação do PNAE (programação, execução e avaliação), as diferenças regionais são expressivas, com o percentual oscilando entre $31,08 \%$ na Região Norte e 44,05\% na Região Sul.

Os resultados dos próbites ajustados permitem identificar algumas variáveis relevantes para a participação do CAE na elaboração do cardápio, na programação, execução e avaliação do programa e no acompanhamento desse serviço nas escolas (Tabela 4).

Os coeficientes obtidos possibilitam verificar que, descartada a influência das demais variáveis, as diferenças regionais têm influência significativa na atividade de programação, execução e avaliação. Conforme mostram os coeficientes do

Tabela 4. Estimativas dos Coeficientes dos Próbites ajustados por atribuição do Conselho Municipal de Alimentação Escolar, 1997.

\begin{tabular}{|c|c|c|c|}
\hline Variáveis explanatórias & Elaboração do cardápio & Programação, execução e avaliação & Acompanhamento nas escolas \\
\hline Intercepto & $-1,568 * *$ & $-2,553 * *$ & $-1,385^{* *}$ \\
\hline NO & $-0,248$ & $-0,089$ & $-0,173$ \\
\hline $\mathrm{CO}$ & 0,233 & $0,385^{* *}$ & 0,246 \\
\hline SU & $-0,424 *$ & $0,281 *$ & $-0,022$ \\
\hline SE & $-0,038$ & $0,266^{*}$ & $-0,116$ \\
\hline Renda 2 & 0,187 & 0,138 & $0,264 *$ \\
\hline Renda 3 & 0,200 & 0,180 & $0,320 *$ \\
\hline Renda 4 & $0,303 * *$ & $0,291 * *$ & $0,424 *$ \\
\hline Renda 5 & $-0,017$ & 0,180 & $0,657^{*}$ \\
\hline TAM 2 & $-0,229 * *$ & 0,093 & $-0,034$ \\
\hline TAM 3 & $-0,130$ & $0,208 * *$ & $-0,092$ \\
\hline TAM 4 & $-0,094$ & $0,234 * *$ & $-0,008$ \\
\hline TAM 5 & $-0,166$ & 0,135 & $-0,144$ \\
\hline PAB & 0,240 & $-0,383^{*}$ & $-0,467^{*}$ \\
\hline PSDB & $-0,182$ & $-0,178$ & $-0,273^{*}$ \\
\hline PFL & 0,083 & 0,084 & $-0,093$ \\
\hline PDT & 0,011 & $-0,013$ & 0,056 \\
\hline PT & 0,154 & 0,321 & 0,117 \\
\hline PSB & 0,273 & $-0,021$ & $-0,157$ \\
\hline PPB & 0,006 & 0,129 & $-0,230 *$ \\
\hline PL & $-0,224$ & 0,098 & $-0,196$ \\
\hline PTB & $-0,163$ & $-0,262$ & $0,308 * *$ \\
\hline M unicipalização & $1,644^{*}$ & $1,781^{*}$ & $1,491 *$ \\
\hline Escolarização & $0,913^{*}$ & $1,149 * *$ & $1,090 *$ \\
\hline Total rural & $-0,2 \mathrm{E}-4$ & $-0,2 \mathrm{E}-4$ & $-0,84 \mathrm{E}-4$ \\
\hline Total urbana & $0,7 \mathrm{E}-5^{* *}$ & $0,13 \mathrm{E}-5$ & $0,58 \mathrm{E}-5$ \\
\hline № Refeição/Dia & $-0,016$ & $-0,015$ & $-0,040$ \\
\hline Comunidade Solidária & 0,078 & 0,018 & 0,072 \\
\hline
\end{tabular}

(*) coeficiente significativo a $5 \% ;(* *)$ coeficiente significativo a $10 \%$. 
modelo ajustado, a probabilidade de o Conselho desempenhar essa função é maior nas cidades das Regiões Centro-Oeste, Sul e Sudeste, tomando-se como base os municípios do Nordeste.

A única outra função para a qual se detectou influência de diferenças regionais foi a elaboração do cardápio. Nessa atribuição, o sinal negativo do coeficiente associado à Região Sul indica que os Conselhos dos municípios dessa Região têm menor probabilidade de desempenhar essa atividade em relação ao Nordeste. As diferenças detectadas entre as demais Regiões e o Nordeste não são significativas.

Quanto ao impacto da renda, os sinais positivos e as magnitudes crescentes apontam que, conforme aumenta a renda familiar per capita média do município, se eleva a probabilidade de o CAE acompanhar esse serviço nas escolas.

Já a influência do tamanho não é conclusiva, pois o fato de o município ter um tamanho relativamente elevado (3 e $4 \circ$ quintos) relaciona-se com a elevação da probabilidade de o Conselho atuar na programação, execução e avaliação do Programa, mas ao mesmo tempo não tem nenhum efeito sobre o acompanhamento do serviço nas unidades escolares, e, ainda, pode afetar negativamente a probabilidade de participar na elaboração do cardápio (o sinal negativo e estatisticamente significativo do coeficiente associado às localidades $2^{\circ}$ quinto de tamanho indica que o CAE dessas cidades tem probabilidade inferior à dos municípios menores de exercer essa atividade).

O partido político do prefeito foi incluído no modelo na suposição de que o CAE dos municípios nos quais o prefeito pertence a partidos políticos com tradição de valorização da participação democrática deveria apresentar atuação mais efetiva. Entretanto, para a grande maioria dos partidos, os coeficientes se revelaram não significativos, ou seja, a influência da participação da população na supervisão do Programa independe do partido político ao qual o prefeito do município está filiado. Algumas exceções foram notadas quanto à influência negativa e estatisticamente significativa de 0 prefeito pertencer a partidos políticos muito pequenos ou estar sem vinculação partidária, no tocante à programação, execução e avaliação e ao acompanhamento do serviço nas unidades escolares ou, ainda, de ele pertencer ao PSDB ou $\mathrm{PPB}$, no tocante à supervisão do atendimento nas escolas.

A inexistência da participação mais efetiva dos Conselhos nas prefeituras administradas por prefeitos filiados a partidos considerados mais "progressistas" pode estar refletindo a inexperiência das prefeituras, dado o período relativamente curto decorrido entre a criação do Conselho em 1995 e o momento em que foi realizada a pesquisa em 1997, e/ou a falta de interesse das mesmas em incentivar 0 envolvimento da comunidade na gestão do Programa.

O total de alunos matriculados na área rural não teve influência significativa em nenhuma atividade, enquanto o total de alunos na área urbana tem influência positiva e estatisticamente significativa apenas em relação à elaboração do cardápio.

0 número de refeições servidas por aluno/dia e o fato de o município pertencer ao Programa Comunidade Solidária não ocasionam nenhum impacto significativo na atuação do CAE.

Por fim, o impacto da descentralização do PNAE é, significativamente, positivo. Os CAE dos municípios cuja modalidade de gerenciamento do Programa de Alimentação Escolar é municipalizada têm maior probabilidade de desempenhar a função de elaboração do cardápio e de acompanhamento do serviço na escola em relação àqueles cujo 0 gerenciamento é feito pela Secretaria Estadual da Educação. Para aqueles que adotam a escolarização, a probabilidade de atuação do Conselho é maior para todas as funções consideradas. Isto parece significar que os Conselhos otimizam o seu funcionamento, se estiverem mais próximos do usuário do Programa. 
Para o caso do PNAE é importante registrar que, também em 1997, Pipitone $(1997)^{6}$ verificou, no Estado de São Paulo, repercussão favorável dos processos de descentralização na melhoria dos cardápios e na aceitação dos mesmos por parte dos escolares, sobretudo em decorrência do aumento do uso de produtos in natura. Além disso, detectou-se, nessa mesma pesquisa, a diminuição do desperdício dos gêneros adquiridos para alimentação escolar. É possível associar tais melhorias às funções do $C A E$, as quais incluem, entre suas prerrogativas, a possibilidade de interferir nas decisões de compra de produtos e na composição dos cardápios do Programa de Alimentação Escolar.

A otimização da atuação dos CAE deverá orientar-se através da vinculação efetiva de suas decisões à participação da população, conforme propõe Vieira $(2001)^{10}$, ao afirmar que os Conselhos deveriam atuar como espaço de ações e mudanças implementadas a partir da avaliação das necessidades do conjunto de seus usuários. Desta forma, seria ampliada a presença dos diferentes segmentos no processo de decisão, configurando-se, assim, em uma instância de importância fundamental ao sucesso do PNAE e não em uma organização figurativa.

\section{O N C L U S Ã O}

A atribuição principal do Conselho, conforme os resultados obtidos, continua a ser a fiscalização da aplicação dos recursos destinados ao PNAE, pois em $76,90 \%$ dos municípios o CAE desempenha essa função, seguida pelo acompanhamento do programa nas unidades escolares, para o qual esse percentual é de $63,45 \%$. Já a participação dos Conselhos na elaboração do cardápio e na programação, execução e avaliação do atendimento é menor, atingindo apenas $50,41 \%$ e $38,90 \%$ dos municípios, respectivamente.

Tais dados sugerem que transformar o participante e/ou usuário do Programa Nacional de Alimentação Escolar em um cidadão ativo, o qual opina, controla e fiscaliza o Programa, por meio da valorização dos Conselhos de Alimentação Escolar, é um processo social a ser ainda consolidado.

A análise dos modelos próbites ajustados permitiu identificar variáveis relevantes para a participação do Conselho em algumas funções. Os coeficientes obtidos indicam a necessidade de uma intervenção dirigida aos municípios das Regiões Norte e Nordeste e aos de menor tamanho, visando o aumento da participação pelos Conselhos na atividade de programação, execução e avaliação do Programa.

Os Conselhos dos municípios da Região Sul, por outro lado, devem ser particularmente estimulados a aumentar sua participação na elaboração do cardápio.

Os resultados desta pesquisa parecem, ainda, confirmar a descentralização e a participação como práticas intrinsecamente vinculadas e auto-reforçadoras. Nesse sentido, nos municípios nos quais a descentralização atinge sua forma mais radical - a escolarização - é, aparentemente, mais efetiva a atuação dos Conselhos.

Finalmente, é importante sugerir a realização de novos estudos na área, dado que o tempo decorrido desde a criação dos CAE pode ter possibilitado uma maior conscientização da população no sentido de participar da gestão dos recursos públicos em serviços de seu próprio interesse.

Fica também como sugestão que as futuras pesquisas procurem complementar as informações obtidas dos agentes implementadores do Programa através de entrevistas com os membros dos $\mathrm{CAE}^{1}$ e análise de documentos, tais como Atas de Reuniões e Pareceres emitidos pelos mesmos.

\section{REFERÊ N CIAS}

1. Lobo T. Descentralização: conceitos, princípios, prática governamental. Cad Pesq 1990; (74):5-10. 
2. McLure CE. Comment on the dangers of descentralization by Prud'Homme. The World Bank Research Observer 1995; 10(2):221-26.

3. Banco Internacional de Reconstrução e Desenvolvimento/Banco Mundial. Relatório sobre o desenvolvimento mundial 2000/2001: luta contra a pobreza. Washington DC: Oxford University Press; 2001.

4. Brasil. Lei n. 8913 de 12/7/1994. Dispõe sobre a descentralização da merenda escolar. Diário Oficial da União 1994; 132(1):30.

5. Brasil. Presidência da República. M edida Provisória 1979-19 de 2/6/2000. Dispõe sobre o repasse de recursos financeiros do Programa de Alimentação Escolar. Diário Oficial da União 2000; Edição Extra. p.1. Disponível em: www.fnde.gov.br/ legislacao

6. Pipitone MAP. Programa de alimentação escolar: um estudo sobre descentralização, escola e educadores [tese]. Campinas: Faculdade de Educação, Unicamp; 1997.

7. Santos L, Mazza RPD, Santos SMC, Santos LMP, Almeida DS, Almeida LC, et al. O Papel do Conselho de Alimentação Escolar sob o enfoque de Segurança Alimentar. In: Livros de Resumos do $17^{\circ}$ Congresso Brasileiro de Ciência e Tecnologia de Alimentos; 2000; Fortaleza. Fortaleza: UFC; 2000. v.3.

8. Ministério da Educação e do Desporto/Instituto Nacional de Estudos e Pesquisas Educacionais. Síntese dos resultados da pesquisa "avaliação da descentralização de recursos do FNDE e da merenda escolar. Campinas: Núcleo de Política Pública/Unicamp, 1997.

9. Instituto Brasileiro de Geografia e Estatística. Censo Demográfico; resultados do universo relativo às características da população e dos domicílios. Rio de Janeiro; 1994.

10. Vieira MNCM. Estudo das representações sociais do Programa de Alimentação Escolar [tese]. Ribeirão Preto: Escola de Enfermagem da Universidade de São Paulo; 2001.

Recebido para publicação em 23 de janeiro e aceito em 13 de agosto de 2002 . 